\title{
Phytopathology
}

\section{Soybean Resistance to the Soybean Cyst Nematode Heterodera glycines: An Update}

\begin{abstract}
Melissa G. Mitchum
Division of Plant Sciences and Bond Life Sciences Center, Columbia, MO 65211.

Accepted for publication 30 June 2016.

ABSTRACT

Mitchum, M. G. 2016. Soybean resistance to the soybean cyst nematode Heterodera glycines: An update. Phytopathology 106:1444-1450.

The soybean cyst nematode (SCN), Heterodera glycines, remains a serious threat to soybean production throughout the world. A lack of genetic diversity in resistant soybean cultivars has led to a widespread shift toward virulence in SCN populations, leaving farmers with few proven options other than nonhost rotation to manage this nematode. Recent advances in our understanding of the genes controlling resistance to the nematode have led to improved molecular markers, which are, in turn, increasing the efficiency and precision of the breeding pipeline. A better understanding of the molecular and biochemical basis of SCN resistance and nematode virulence will provide information useful for the development of a long-term strategic plan for diversification and the deployment of cultivars that protect current sources of natural resistance while identifying new targets for engineering novel resistance.
\end{abstract}

Soybean (Glycine max (L.) Merr.) is an important protein and oil crop. The United States annually produces 33\% of the world's soybean with a total value of $\$ 34.5$ billion, ranking first in the world followed by Brazil (31\%), Argentina (18\%), and China (4\%) (http:// SoyStats.com, 2016). Soybean cyst nematode (SCN) Heterodera glycines (Ichinohe), a worldwide problem wherever soybeans are grown, is a continuing threat to producers. Since its first detection in 1954 from a single county in North Carolina (Winstead et al. 1955), SCN has spread to nearly every soybean-producing state in the United States (Tylka and Marrett 2014) and is estimated to cause more than $\$ 1.2$ billion in annual yield losses (Koenning and Wrather 2010), making it the most damaging pathogen of soybean. SCN was first detected in Brazil in the early 1990s and has since spread throughout South America. Similarly, SCN continues to spread across soybean producing regions of China (Peng et al. 2016; Wang et al. 2015a) with detection in 15 provinces and yield loss estimates of more than $\$ 120$ million (Wang et al. 2015b).

\section{LESS THAN DESIRABLE DIVERSITY FOR RESISTANCE}

SCN is primarily managed through deployment of resistant cultivars. However, widespread use of resistance has caused major shifts in nematode populations that are now adapted to reproduce on

Corresponding author: M. G. Mitchum; E-mail address: goellnerm@missouri.edu

http://dx.doi.org/10.1094/PHYTO-06-16-0227-RVW

(C) 2016 The American Phytopathological Society resistant cultivars. Historically, Peking and PI 88788 have been the predominant sources of resistance in North American cultivars (reviewed in Concibido et al. 2004). In recent years, more than $95 \%$ of the market share in the north central United States has shifted to PI 88788-type resistance; the remaining cultivars derive resistance from Peking, PI 437654, or combinations thereof (Joos et al. 2013; Tylka and Mullaney 2015). This market practice has led to repeated use of the same type of resistance and adaptation of SCN to these sources. An increase in the number of SCN populations adapted to cultivars with PI 88788 resistance was documented more than 10 years ago (Mitchum et al. 2007; Niblack et al. 2008). Concern continues as recent statewide surveys are reporting a further increase in the number of SCN populations that can grow on this source of resistance as well as higher female indices of these populations on PI 88788 (A. Howland and M. G. Mitchum, unpublished data).

\section{AN INTIMATE ASSOCIATION}

SCN infective second-stage juveniles (J2) hatch from eggs in the soil and are attracted to the roots of soybean plants (Fig. 1). Upon reaching the root surface, the juvenile uses a hollow mouth spear (stylet) to pierce the plant cell wall while secreting digestive enzymes to aid intracellular migration through the root cortex toward the vascular cylinder. As a requirement of its obligate sedentary lifestyle, the SCN then selects a single cell near the vascular tissue to initiate the formation of a permanent feeding site (syncytium). The immobilized nematode remains at this location for the remainder of its life cycle, sequestering essential nutrients 
needed to reach reproductive maturity. The feeding site forms by progressive cell wall dissolution and incorporates hundreds of cells as it expands longitudinally along the length of the root while the nematode feeds. Other characteristics of the developing syncytium include a dense cytoplasm, hypertrophied nuclei, increased organelle content, and the formation of cell wall ingrowths along walls adjacent to vascular tissues to increase the plasma membrane surface area to meet the high demand for solute uptake (Endo 1965). As such, the syncytium becomes a highly metabolically active nutrient sink. Thus, it is no surprise that the vulnerability of the feeding cell has been exploited by the plant immune system as a means to acquire resistance and is a prime target for engineered resistance.

\section{INSIDE THE FEEDING CELL OF A RESISTANT PLANT}

Though penetration of the nematode into roots of resistant soybeans is not impacted, its further development into a mature female is significantly hampered ( $\mathrm{Li}$ et al. 2004). The underlying mechanism of resistance to this parasite remains unclear, but this observation alone points to an inability to properly establish and/or maintain a feeding cell. But does the plant deploy a direct attack on the nematode that leads to feeding cell demise, or is the resistance a local attack on itself to ward off the nematode? And, are there differences at a cellular level among resistant sources? This conundrum has led to several studies focused on discerning the earliest events taking place and the genes expressed within the feeding cells of resistant soybean before they die in response to nematode parasitism (Fig. 1). Early histological studies of degenerating feeding cells in resistant cultivar Peking suggest an active defense response by the host marked by nuclear degeneration and necrosis that is accompanied by abnormal secondary cell wall thickenings reminiscent of the hypersensitive response to pathogen infection (Endo 1965; Riggs et al. 1973). Later studies noted differences in both the timing and cellular features of the resistance response associated with different sources of resistance (Acedo et al. 1984; Kim et al. 1987, 2010b, 2012; Mahalingam and Skorupska 1996); Peking, PI 89772, and PI 437654, or cultivars developed from these sources, exhibit rapid syncytium degeneration, whereas PI 88788 and PI 209332, or cultivars developed from these sources, exhibit a slower degeneration of the syncytium, although resistance is just as potent. The differences in timing are also accompanied by different subcellular features within the developing syncytium (Fig. 1). Although necrosis is the end result, the precipitating events differ between lines exhibiting rapid versus slow degeneration. One of the earliest events, documented at 2 days after inoculation (DAI), in lines undergoing a rapid resistance response is dilation of the rough endoplasmic reticulum (RER), a clear sign of ER dysfunction (Kim et al. 2012). This event is followed by formation of cell wall appositions and subsequent necrosis of the developing syncytium and surrounding cells by 5 DAI (Kim et al. 1987, 2010b). In lines such as PI 88788, necrosis is initiated outside the cell wall of the developing syncytium, while nuclear degeneration and chromatin-like material are observed

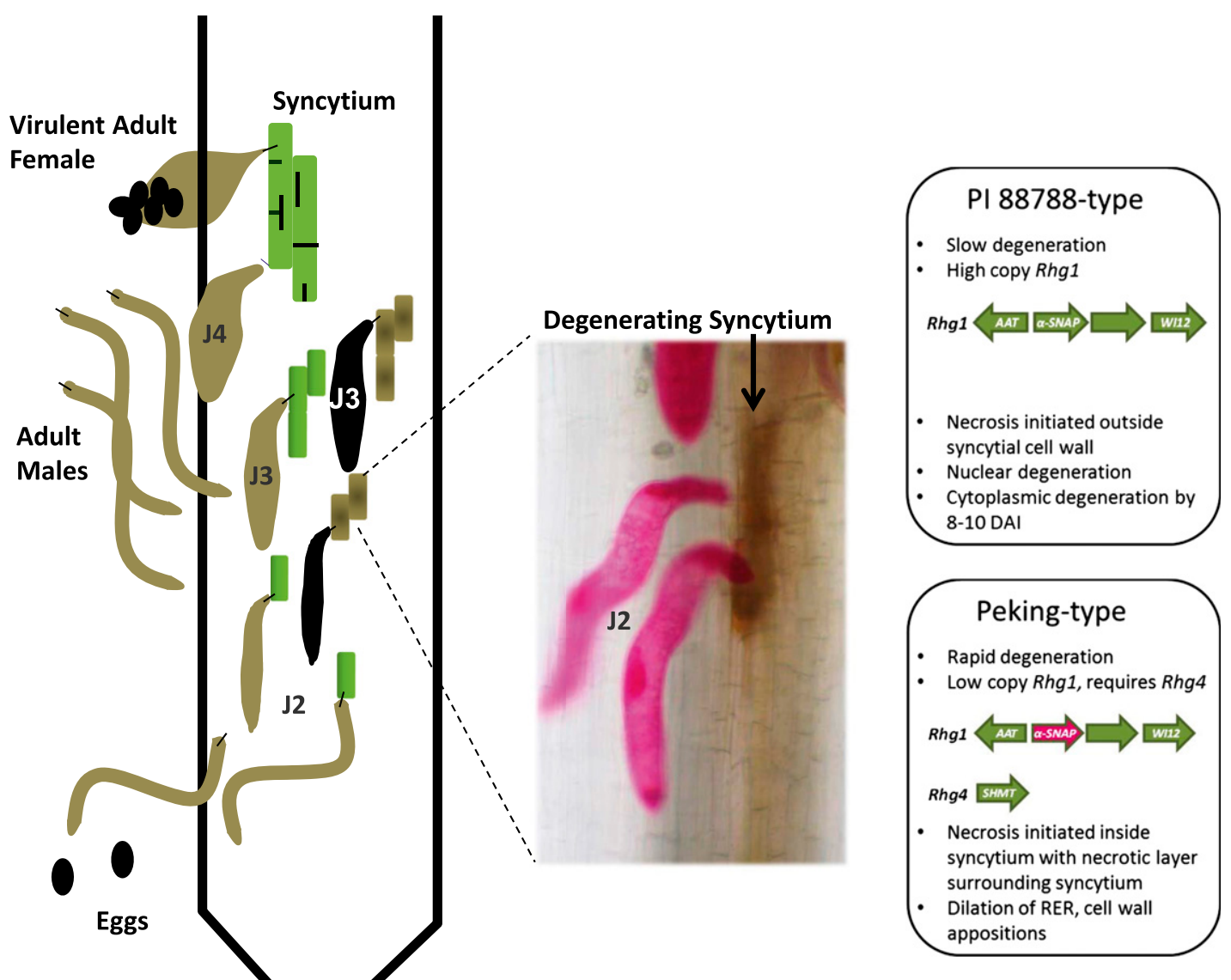

\section{FIGURE 1}

Cartoon diagram of the life cycle of the soybean cyst nematode (SCN) in a Peking-type resistant soybean plant with a photograph of a degenerating syncytium being fed upon by two dying second-stage juvenile nematodes (SCN Hg type 0) stained with acid fuchsin (Daykin and Hussey 1985). Photograph taken by Xiaohong Liu. The two black boxes highlight the features of PI 88788 and Peking types of resistance to SCN Hg Type 0 (Kim et al. 1987, 2010b, 2012). J2, second-stage juvenile; J3, third-stage juvenile; and J4, fourth-stage juvenile. 
within the syncytium cytoplasm. The necrosis engulfs the entire syncytium by 8 to 10 DAI (Kim et al. 1987, 2010b). These distinct structural modifications of degenerating syncytia may reflect differences in the resistance genes of these lines (Kim et al. 2010b). Consistent with these morphological observations, cellspecific transcriptomics of degenerating feeding cells in resistant and susceptible soybean have revealed molecular signatures suggestive of ER dysfunction, formation of cell wall appositions, and apoptotic and autophagic programmed cell death processes (Kandoth et al. 2011; Matsye et al. 2011). A direct comparison of the transcriptional profiles of degenerating syncytia in PI 88788 and Peking supports a model where differences in gene expression amplitude may overlie a conserved transcriptional program (Klink et al. 2011). Consistent with this model, the cloning of the Rhgl and Rhg4 (for resistance to Heterodera glycines) resistance genes (described below) supports at least two potentially related, yet distinct mechanisms of resistance to SCN Hg type 0 to date.

\section{GENES FOR RESISTANCE ELUCIDATED}

It is intriguing that soybean resistance to $\mathrm{SCN}$ has turned out to be nothing like that of Solanaceae resistance to sedentary endoparasitic nematodes, such as the potato cyst nematode (Ernst et al. 2002; Paal et al. 2004) and the root-knot nematode (Jablonska et al. 2007; Milligan et al. 1998). In tomato and potato, the resistance genes belong to classical CC-NB-LRR and TIR-NB-LRR resistance gene families, and even the extracellular resistance gene $C f 2$ has been shown to play a dual role in resistance to nematodes and fungi (Lozano-Torres et al. 2012; reviewed in Kandoth and Mitchum 2013). In fact, the lure of "being just like the others" was so strong, that the soybean community was misled for almost a decade due to the assumption that LRR-RLKs in the mapped region of two major QTLs (rhgl and Rhg4) for SCN resistance were the genes for resistance. As the saying goes "The proof of the pudding is in the eating," so it is that proof of the resistance genes is in actual experimentation. Ultimately, actual experimentation demonstrated that the LRR-kinase genes at the rhgl and Rhg4 loci are indeed independent of resistance to SCN (Liu et al. 2011; Melito et al. 2010). These findings spurred the community to refine the maps, but nothing remotely "classical" remained in the intervals (Kim et al. 2010a). In retrospect, the delay was beneficial in light of the parallel advancements being made by the soybean genomics community. A genome was published (Schmutz et al. 2010), mutagenized populations were generated (Cui et al. 2013; Mathieu et al. 2009), TILLING approaches were developed (Cooper et al. 2008), and silencing approaches were optimized and adapted for studying a root parasite (Kandoth et al. 2013; Liu et al. 2012). This integrated set of functional genomics tools with which to characterize candidate genes for a role in $\mathrm{SCN}$ resistance was invaluable; timing was critical to discovery. The discovery that $r h g 1-b$ in PI 88788-type resistance is conferred by 10 tandem copies of a $31-\mathrm{kb}$ segment containing three dissimilar genes that each contribute to resistance made headlines (Cook et al. 2012), as did the discovery that the gene at the Rhg4 locus with a role in Peking-type resistance is a serine hydroxymethyltransferase (SHMT) (Liu et al. 2012).

The three genes within a $31-\mathrm{kb}$ repeat segment at $r h g 1-b$ shown to contribute to SCN resistance in gene silencing studies include an amino acid transporter, an N-ethylmaleimide-sensitive factor attachment protein ( $\alpha$-SNAP), and a wound-inducible protein (WI12) (Cook et al. 2012). The 31-kb segment at $r h g 1-b$ is present as a single copy in the susceptible soybean cultivar Williams 82 but as three copies in the SCN-resistant cultivar Peking and as 10 copies in the SCN-resistant cultivar Fayette. The higher copy number of these genes results in elevated expression in resistant cultivars. Simultaneous overexpression of these three genes in susceptible soybeans confers partial resistance to SCN (Cook et al. 2012).
In follow-up studies, the Rhgl locus was found to harbor clear signatures of selection as genetic variation across soybean accessions was revealed (Cook et al. 2014; Lee et al. 2015). The evidence for the existence of different Rhgl alleles among resistance sources, first shown through genetic studies (Brucker et al. 2005), could now be explained by classifying sources into groups that differed in copy number and sequence composition: (i) accessions, such as PI 88788, that have a variable high copy number of Rhgl (i.e., 7 to 10 copies of the 31-kb repeat segment) and (ii) accessions, such as Peking, that have a variable low copy number of Rhgl (i.e., 1 to 3 copies) and a new allele of $\alpha$-SNAP. The differences between the susceptible $\alpha$-SNAP allele and the two resistant $\alpha$-SNAP alleles reside in the C-terminal domain (Cook et al. 2014; Lee et al. 2015). In addition to copy number and sequence, differential methylation at Rhgl also correlates with $\mathrm{SCN}$ resistance (Cook et al. 2014). Aside from annotations based on sequence homology, we have limited information about the functions of the three soybean genes identified to play a role in resistance. Therefore, understanding the function of these genes in resistance to SCN and determining how methylation patterns may be contributing to their regulation will be necessary to gain new insights into the biochemical mechanisms of the Rhglmediated resistance.

Genetic mapping studies have established that PI 88788-type resistance requires $R h g l$, whereas Peking-type resistance has the additional requirement of $R h g 4$ to confer resistance to SCN HG type 0 (race 3) (Concibido et al. 2004; Meksem et al. 2001). As it turns out, low copy Rhgl correlates with a requirement of Rhg 4 in SCNresistant accessions (Lee et al. 2015). The SHMT encoded by Rhg4 is a predicted cytosolic enzyme that differs by two amino acids from the susceptible isoform (Liu et al. 2012). Structural modeling of SHMT showed that these polymorphisms, which reside in the folate and pyridoxal-5-phosphate (vitamin B6) binding sites of the enzyme, underlie its gain of function in SCN resistance. SHMTs belong to multigene families in plants with members localized in the cytoplasm, plastids, mitochondria, and nucleus (Zhang et al. 2010). One of the main functions of SHMT is to catalyze the reversible reaction of serine and tetrahydrofolate (THF) to glycine and 5 to 10 methylene tetrahydrofolate (MTHF), thus providing 1-C units for numerous downstream products important for DNA synthesis, cellular methylation, and plant defense. Differences in enzymatic activity between the resistant and susceptible isoforms of SHMT have been observed (Liu et al. 2012), but whether these differences lead to perturbations in folate homeostasis and how this contributes to $\mathrm{SCN}$ resistance remains to be shown. Moreover, how the Rhgl and Rhg4 loci interact to confer resistance remains to be determined on a molecular level.

A recent study investigated the evolution of the $R h g 4$ gene and closely related homologs in cultivated and wild soybean. The Rhg4 gene on chromosome 8 (SHMT08) has a closely related homolog on chromosome 5 (SHMT05). These two genes, which possess the same length and structure, are derived from a whole genome duplication event that occurred 13 million years ago (Schmutz et al. 2010). Sequencing of these two genes in 33 cultivated and 68 wild soybeans revealed that the SCN-resistant allele is absent from wild soybeans and likely emerged via artificial selection during the domestication of soybean (Wu et al. 2016). A study to determine the genetic basis of SCN resistance in the wild soybean $G$. soja accession PI 468916 mapped two resistance QTLs independent of Rhgl and Rhg4 onto chromosomes 15 and 18 (Kim and Diers 2013; Wang et al. 2001); studies are underway to clone the underlying genes for resistance. Stacking of these G. soja alleles with Rhgl and $R h g 4$ provides added protection against the nematode (Kim et al. 2011), suggesting that the underlying genes may differ from those at Rhgl and Rhg4.

Though the complexity of the SCN-soybean interaction was evident, no one expected soybean resistance to $\mathrm{SCN}$ to be controlled 
by a group of dissimilar genes at multiple loci and copy number variation. This surprising finding has confounded researchers and will require a level of investigation that goes well beyond the one gene model.

\section{A NEW ERA OF BREEDING}

Of the more than 100 resistance sources identified, minimal genetic diversity within this pool has hampered diversification of resistance in deployed cultivars (Arelli et al. 2000; Concibido et al. 2004). "Resistant to soybean cyst nematode race 3 and race 14 " is the typical label found on a bag of SCN-resistant soybean seed. Determining the actual source of resistance in the seed takes a bit more effort. As alluded to above, the current diversity of SCN resistance in commercial cultivars is less than desirable; there is more than a $95 \%$ chance that a chosen northern U.S. cultivar will carry the $r h g 1-b$ allele originating from PI 88788. However, new knowledge that both gene copy number and sequence correlate with the SCN resistance phenotype requires a revision to current breeding protocols. With the newly discovered resistance gene identities, robust SNP marker development has followed in the wake that not only facilitates high-throughput selection of SCN resistance, but also the ability to distinguish between Rhgl resistance alleles for improved breeding accuracy (Shi et al. 2015). In addition, quantitative genomic PCR and TaqMan assays can now be used to predict Rhgl copy number (Lee et al. 2015; Kadam et al. 2016). Whereas the observed variation in the effectiveness of SCN-resistant cultivars labeled as resistant to race 3, despite the use of the PI 88788 source, may be due in part to genotypic differences in the SCN populations used in screening during cultivar development (Niblack et al. 2006), it is now evident that copy number at $r h g 1-b$ might actually explain a large part of this variation, warranting a reevaluation of current commercial cultivars. The nematode itself is also an excellent indicator of the relatedness of resistance sources and can be used to assist in breeding and strategic deployment efforts. For example, HG type served as a predictor of shared resistance genes among PI 88788, PI 209332, and Cloud (PI 548402) and those in Peking, PI 90763 , and PI 89772 (Colgrove and Niblack 2008). These observations are consistent with the finding that different Rhgl alleles exist in these two groups of resistance, the latter of which also requires $R h g 4$. Studies to evaluate how the nematode adapts to various resistance gene combinations will aid in determining which resistance gene stacks will be most effective and how best to deploy them in rotation.

\section{WHAT CAN THE NEMATODE TELL US?}

With what appears to be multiple mechanisms of resistance emerging from the plant side, it is no surprise that the nematode side of the equation appears to be equally complicated and involves multiple dominant and recessive genes for virulence. Although virulence genes were reported in genetic studies as early as the 1990s (Dong and Opperman 1997), they have eluded researchers due to the lack of physical and genetic maps necessary for mapbased cloning studies. The Joint Genome Institute (JGI) recently completed a draft assembly of an SCN genome. However, its A-T rich and repetitive nature has presented difficulty for a high-quality assembly. Therefore, additional efforts are underway to improve and annotate the current draft genome assembly. In the absence of a genetic infrastructure, whole genome SNP discovery approaches were explored for identifying virulence genes (Bekal et al. 2008). More recently, two very interesting gene candidates have been implicated in nematode virulence through a genetic mapping study that employed a whole genome allelic imbalance analysis/bulk segregant-based approach to identify SNPs linked to virulence genes. The candidate genes include a biotin synthase $(\mathrm{HgBioB})$ and a putative SNARE domain $(H g S L P-1)$ containing protein with homology to bacterial proteins (Bekal et al. 2015). HgSLP-1 appears to be deleted in virulent SCN. The gene encodes a protein with a coiled-coil domain sharing similarity to members of the target soluble SNAP receptor domain superfamily (t-SNARE) predicted to be involved in membrane fusion events. Interestingly, one gene at the $r h g l-b$ locus encodes a predicted $\alpha$-SNAP protein. Since t-SNAREs interact with $\alpha$-SNAP during membrane fusion events, the authors tested whether this nematode protein might directly interact with the resistance protein and present some preliminary in vitro data to support a potential interaction. Though secretion of HgSLP-1 in planta remains to be shown, the predicted secreted protein is localized in subventral esophageal gland cells of nematodes infecting the roots of susceptible soybeans, suggesting that it may play an important role in parasitism (Bekal et al. 2015). The potential exists that a direct interaction of HgSLP-1 from an avirulent nematode with the rhgl- $b \alpha$-SNAP is the trigger for resistance and that the loss of this gene in virulent nematodes serves as a mechanism to evade plant resistance. Silencing studies of $H g S L P-1$ in an avirulent SCN population showing that the nematodes regain the ability to grow on resistant lines is needed to validate this hypothesis.

Other than the detection of SNPs between avirulent and virulent SCN populations, little is known about the $\mathrm{HgBioB}$ candidate. Biotin is a critical cellular molecule with a variety of roles, including as a precursor for biotin dependent carboxylases essential for fatty acid metabolism and amino acid catabolism. The authors speculate that amino acid polymorphisms between avirulent and virulent SCN populations may underlie differences in enzymatic activity that allow the nematode to circumvent resistance (Bekal et al. 2015). Functional studies are needed to establish any role in virulence.

Clearly, there is still much to learn about how SCN adapts to overcome or evade host plant resistance. While a fully annotated SCN genome is actively being pursued by the community (http:// jgi.doe.gov/why-sequence-the-soybean-cyst-nematode/), RNA sequencing of SCN populations that differ in their ability to reproduce on resistant soybeans is facilitating comparative transcriptomic studies to better understand aspects of SCN parasitism and adaptation to resistant cultivars (M. Gardner and M. G. Mitchum, unpublished data). The molecular details of nematode virulence will assist researchers not only in understanding plant resistance mechanisms, but also will open the door for novel strategies to engineer resistance and better diagnostic tools to predict population virulence.

\section{PLANT-GENE MEDIATED TRANSGENIC APPROACHES FOR RESISTANCE TO SCN}

One potential strategy to improve SCN resistance is to exploit the new knowledge of SCN resistance genes and add more copies of $R h g l$. Additionally, a stack of $R h g 4$ and the high copy $R h g l$ allele or combining both types of Rhgl alleles using transgenic approaches might broaden resistance to SCN. However, recent studies, including our own, seem to indicate that the predicted outcome of these gene stacks may not be so simple and, in some cases, may be context dependent. Further testing is currently underway to evaluate the utility of cisgenic approaches and the potential for stacking Rhg alleles.

In an effort to head off the inevitable adaptation of SCN to resistance genes, researchers have been searching for alternative ways to enhance resistance by overexpressing plant defense genes or silencing plant susceptibility genes in soybean. Although these approaches have shown some potential, no transgenic nematode 
resistance trait is currently available on the market. The genes used in these studies have been identified from a wealth of microarray experiments profiling gene expression changes in resistant and susceptible soybean in response to SCN on both global (Klink et al. 2007; Mazarei et al. 2011) and cellular levels (Kandoth et al. 2011; Klink et al. 2010, 2011; Matsye et al. 2011) or have been identified as targets of nematode secreted effectors to promote parasitism (reviewed in Hewezi and Baum 2013; Gardner et al. 2015). In a study by Matthews et al. (2013), 100 soybean genes selected from microarray studies were individually overexpressed in susceptible soybean roots and assessed for impacts on SCN development. Of these, nine genes resulted in female indices between 26 to $50 \%$, a moderate level of resistance to $\mathrm{SCN}$; the lowest female index reported $(26 \%)$ equates to a $65 \%$ reduction in SCN development in lines overexpressing an ascorbate peroxidase gene. It remains to be shown whether overexpression of these genes has any detrimental effects on plant growth and development and, if so, whether specific expression in feeding cells using nematodeinducible promoters would improve their utility (Kandoth et al. 2011; Liu et al. 2014).

Modulation of the salicylic acid (SA) pathway holds some promise for engineering enhanced resistance to SCN. Several SA pathway genes have been shown to be upregulated in resistant soybean in response to SCN infection (Kandoth et al. 2011; Klink et al. 2007, 2011; Mazarei et al. 2011), despite any functional evidence of whether SA plays a role in Rhg1- and Rhg4-mediated resistance. However, expression of $N a h G$ in susceptible soybean roots led to a further increase in susceptibility to SCN, demonstrating a potential role for SA in basal defense against this nematode (X. Liu and M. G. Mitchum, unpublished data). Studies have reported reductions in $\mathrm{SCN}$ infection of soybean ranging from 33 to $68 \%$ by the overexpression of AtICS1, AtNPR1, AtTGA2, AtPR-5, and AtPAD4. All Arabidopsis genes known to be involved in the regulation and biosynthesis of SA, providing initial support for the potential modulation of the SA pathway to engineer enhanced resistance to SCN (Matthews et al. 2014; Youssef et al. 2013). Since these studies were conducted in composite plants, any effects on plant growth and development were not assessed nor were metabolite profiles measured to try to understand the basis of this resistance. On the other hand, one gene showing particular promise that has been advanced to stable transgenics is GmSAMT1 (S-adenosyl-L-methionine [SAM]-dependent salicylic acid carboxyl methyltransferase 1), which encodes an enzyme that catalyzes the methylation of SA to form methyl salicylate (MeSA). GmSAMT1 is significantly upregulated in resistant soybean in response to SCN infection (Mazarei et al. 2011). Transgenic hairy roots overexpressing GmSAMT1 in different SCN-susceptible genotypes enhanced resistance to SCN by 53.4 to $72.4 \%$ (Lin et al. 2013). A follow-up study in stable soybean transgenics reported enhanced resistance to multiple HG types of SCN in greenhouse studies and no difference in seed yields between wild-type and transgenic soybeans when grown in a 1-year field trial with negligible SCN levels (Lin et al. 2016). Percent reduction in nematode development on the transgenic lines ranged from 43 to $79 \%$ relative to controls. The mechanism underlying the enhanced resistance phenotype by overexpressing GmSAMT1 is unclear. MeSA levels in transgenic roots were below detectable limits in metabolite profiling studies, and the levels of SA, benzoic acid (SA precursor), and phenylalanine (PA) were measured only in the leaves of the transgenic plants, not roots. In the leaves, the levels of SA and BA decreased, whereas PA levels increased. The authors speculate that changes in leaf metabolites might create a nutritional deficiency leading to the enhanced resistance, but a more detailed metabolite analysis in roots is certainly warranted.

An alternative strategy for enhancing resistance to $\mathrm{SCN}$ is through inactivation or modification of plant susceptibility $(S)$ genes, which now can be achieved using a variety of different methodologies (Fosu-Nyarko and Jones 2015). Numerous $S$ genes encoding proteins targeted by nematode effector proteins to promote parasitism have been identified (Gardner et al. 2015; Hewezi and Baum 2013). Guo et al. (2015) was the first to report a proof-of-concept study demonstrating enhanced resistance in soybean to SCN by targeting an $S$ gene. Although this approach may require some creative engineering, an approach that stacks $R$ and $S$ genes may prove to be a viable approach for improving soybean resistance to $\mathrm{SCN}$ as well as prolong the durability of natural resistance.

\section{FUTURE PROSPECTS}

Using a single source of resistance is not a viable long-term strategy for managing any pathogen, let alone a sexually reproducing nematode that can readily adapt to resistant cultivars. While the vast majority of growers are planting SCN-resistant soybeans, the threat of nematodes overcoming this resistance is not on the radar of many farmers. Even if it were, little has changed when it comes to SCN management. On the contrary, the point of view of plant nematologists and geneticists has dramatically changed with the discovery of genes underlying SCN resistance. This new knowledge presents a unique opportunity to breed with greater efficiency and precision while utilizing the nematode as a tool to evaluate adaptation to different types of resistance in an effort to develop a long-term strategic plan for diversification and deployment of cultivars. The fact is SCN is here to stay, but will we change our approach to manage it into the future by harnessing the knowledge gained about resistance in a strategic breeding and deployment program? The type of change needed will require productive public-private partnerships to transform the marketplace and to provide new solutions to farmers. Understandably, change is never easy, but an unwillingness to change breeds complacency and resistant nematodes!

\section{ACKNOWLEDGMENTS}

I thank the various funding agencies who have supported our $\mathrm{SCN}$ research program through the years including Missouri Soybean Merchandising Council, United Soybean Board, North Central Soybean Research Program, National Science Foundation, USDA-NIFA, as well as the postdoctoral fellows, students, staff scientists, and many colleagues who have contributed to the research findings described in this review. I also thank M. Kroll for proofreading the manuscript.

\section{LITERATURE CITED}

Acedo, J. R., Dropkin, V. H., and Luedders, V. D. 1984. Nematode population attrition and histopathology of Heterodera glycines-soybean associations. J. Nematol. 16:48-57.

Arelli, P. R., Sleper, D. A., Yue, P., and Wilcox, J. A. 2000. Soybean reaction to races 1 and 2 of Heterodera glycines. Crop Sci. 40:824-826.

Bekal, S., Craig, J. P., Hudson, M. E., Niblack, T. L., Domier, L. L., and Lambert, K. N. 2008. Genomic DNA sequence comparison between two inbred soybean cyst nematode biotypes facilitated by massively parallel 454 micro-bead sequencing. Mol. Gen. Genet. 279:535-543.

Bekal, S., Domier, L. L., Gonfa, B., Lakhssassi, N., Meksem, K., and Lambert, K. N. 2015. A SNARE-like protein and biotin are implicated in soybean cyst nematode virulence. PLoS One 10:e0145601.

Brucker, E., Carlson, S., Wright, E., Niblack, T., and Diers, B. 2005. Rhg1 alleles from soybean PI 437654 and PI 88788 respond differentially to isolates of Heterodera glycines in the greenhouse. Theor. Appl. Genet. 111:44-49.

Colgrove, A. L., and Niblack, T. L. 2008. Correlation of female indices from virulence assays on inbred lines and field populations of Heterodera glycines. J. Nematol. 40:39-45.

Concibido, V. C., Diers, B. W., and Arelli, P. R. 2004. A decade of QTL mapping for cyst nematode resistance in soybean. Crop Sci. 44:1121-1131.

Cook, D. E., Bayless, A. M., Wang, K., Guo, X., Song, Q., Jiang, J., and Bent, A. F. 2014. Distinct copy number, coding sequence, and locus methylation 
patterns underlie Rhg1-mediated soybean resistance to soybean cyst nematode. Plant Physiol. 165:630-647.

Cook, D. E., Lee, T. G., Guo, X., Melito, S., Wang, K., Bayless, A., Wang, J., Hughes, T. J., Willis, D. K., Clemente, T. E., Diers, B. W., Jiang, J., Hudson, M. E., and Bent, A. F. 2012. Copy number variation of multiple genes at Rhgl mediates nematode resistance in soybean. Science 338:1206-1209.

Cooper, J. L., Till, B. J., Laport, R. G., Darlow, M. C., Kleffner, J. M., Jamai, A., El-Mellouki, T., Liu, S., Ritchie, R., Nielsen, N., Bilyeu, K. D., Meksem, K., Comai, L., and Henikoff, S. 2008. TILLING to detect induced mutations in soybean. BMC Plant Biol. 20088:9.

Cui, Y., Barampuram, S., Stacey, M. G., Hancock, C. N., Findley, S., Mathieu, M., Zhang, Z., Parrott, W. A., and Stacey, G. 2013. Tnt1 retrotransposon mutagenesis: A tool for soybean functional genomics. Plant Physiol. 161: 36-47.

Daykin, M. E., and Hussey, R. S. 1985. Staining and histopathological techniques in nematology. Pages 39-48 in: An advanced treatise on Meloidogyne. K. R. Barker, C. C. Carter, and J. N. Sasser, eds. North Carolina State University Press, Raleigh, North Carolina.

Dong, K., and Opperman, C. H. 1997. Genetic analysis of parasitism in the soybean cyst nematode Heterodera glycines. Genetics 146:1311-1318.

Endo, B. Y. 1965. Histological responses of resistant and susceptible soybean varieties, and backcross progeny to entry and development of Heterodera glycines. Phytopathology 55:249-372.

Ernst, K., Kumar, A., Kriseleit, D., Kloos, D. U., Phillips, M. S., and Ganal, M. W. 2002. The broad-spectrum potato cyst nematode resistance gene (Hero) from tomato is the only member of a large gene family of NBS-LRR genes with an unusual amino acid repeat in the LRR region. Plant J. 31: 127-136.

Fosu-Nyarko, J., and Jones, M. G. K. 2015. Application of biotechnology for nematode control in crop plants. Pages 339-376 in: Advances in Botanical Research Vol. 73, Plant Nematode Interactions: A View on Compatible Interrelationships. Chapter 14. C. Escobar and C. Fenoll, eds. Elsevier, Oxford.

Gardner, M., Verma, A., and Mitchum, M. G. 2015. Emerging roles of cyst nematode effectors in exploiting plant cellular processes. Pages 259-291 in: Advances in Botanical Research Vol. 73, Plant Nematode Interactions: A View on Compatible Interrelationships. Chapter 11. C. Escobar and C. Fenoll, eds. Elsevier, Oxford.

Guo, X., Chronis, D., De La Torre Cuba, C. M., Smeda, J., Wang, X., and Mitchum, M. G. 2015. Enhanced resistance to soybean cyst nematode Heterodera glycines in transgenic soybean by silencing putative CLE receptors. Plant Biotechnol. J. 13:801-10.

Hewezi, T., and Baum, T. J. 2013. Manipulation of plant cells by cyst and rootknot nematode effectors. Mol. Plant-Microbe Interact. 26:9-16.

Jablonska, B., Ammiraju, J. S., Bhattarai, K. K., Mantelin, S., Martinez de Illarduya, O., Roberts, P. A., and Kaloshian, I. 2007. The Mi-9 gene from Solanum arcanum conferring heat-stable resistance to root-knot nematodes is a homolog of Mi-1. Plant Physiol. 143:1044-1054.

Joos, D. K., Esgar, R. W., Henry, B. R., and Nafziger, E. D. 2013. Soybean variety test results in Illinois-2013. Crop Sciences Special Report 2013-04. University of Illinois, Urbana.

Kadam, S., Vuong, T. D., Qui, D., Meinhardt, C. G., Song, L., Deshmukh, R., Patil, G., Wan, J., Valliyodan, B., Scaboo, A. M., Shannon, J. G., and Nguyen, H. T. 2016. Genomic-assisted phylogenic analysis and marker development for next generation soybean cyst nematode resistance breeding. Plant Sci. 242:342-350.

Kandoth, P., Heinz, R., Yeckel, G., Gross, N. W., Juvale, P. S., Hill, J., Whitham, S. A., Baum, T. J., and Mitchum, M. G. 2013. A virus-induced gene silencing method to study soybean cyst nematode parasitism in Glycine max. BMC Res. Notes 6:255.

Kandoth, P. K., Ithal, N., Recknor, J., Maier, T., Nettleton, D., Baum, T. J., and Mitchum, M. G. 2011. The soybean Rhg1 locus for resistance to the soybean cyst nematode Heterodera glycines regulates expression of a large number of stress- and defense-related genes in degenerating feeding cells. Plant Physiol. 155:1960-1975.

Kandoth, P. K., and Mitchum, M. G. 2013. War of the worms: How plants fight underground attacks. Curr. Opin. Plant Biol. 16:457-463.

Kim, M., and Diers, B. W. 2013. Fine mapping of the SCN resistance QTL cqSCN-006 and cqSCN-007 from Glycine soja PI 468916. Crop Sci. 53: 775-785.

Kim, M., Hyten, D. L., Bent, A. F., and Diers, B. W. 2010a. Fine mapping of the SCN resistance locus $r h g 1-b$ from PI 88788. Plant Genome 3:81-89.

Kim, M., Hyten, D. L., Niblack, T. L., and Diers, B. W. 2011. Stacking resistance alleles from wild and domestic soybean sources improves soybean cyst nematode resistance. Crop Sci. 51:934-943.

Kim, Y. H., Kim, K. S., and Riggs, R. D. 2010b. Differential subcellular responses in resistance soybeans infected with soybean cyst nematode races. Plant Pathol. J. 26:154-158.
Kim, Y. H., Kim, K. S., and Riggs, R. D. 2012. Initial subcellular responses of susceptible and resistant soybeans infected with the soybean cyst nematode. Plant Pathol. J. 28:401-408.

Kim, Y. H., Riggs, R. D., and Kim, K. S. 1987. Structural changes associated with resistance of soybean to Heterodera glycines. J. Nematol. 19:177187.

Klink, V. P., Hosseini, P., Matsye, P. D., Alkharouf, N. W., and Matthews, B. F. 2011. Differences in gene expression amplitude overlie a conserved transcriptomic program occurring between the rapid and potent localized resistant reaction at the syncytium of the Glycine max genotype Peking (PI 548402) as compared to the prolonged and potent resistant reaction of PI 88788. Plant Mol. Biol. 75:141-165.

Klink, V. P., Overall, C. C., Alkharouf, N. W., MacDonald, M. H., and Matthews, B. F. 2007. A time-course comparative microarray analysis of an incompatible and compatible response by Glycine max (soybean) to Heterodera glycines (soybean cyst nematode) infection. Planta 226:1423-1447.

Klink, V. P., Overall, C. C., Alkharouf, N. W., MacDonald, M. H., and Matthews, B. F. 2010. Microarray detection call methodology as a means to identify and compare transcripts expressed within syncytial cells from soybean (Glycine max) roots undergoing resistant and susceptible reactions to soybean cyst nematode (Heterodera glycines). J. Biomed. Biotechnol. 2010:491217.

Koenning, S. R., and Wrather, J. A. 2010. Suppression of soybean yield potential in the continental United States from plant diseases estimated from 2006 to 2009. Plant Health Prog. Published online. doi:10.1094/PHP-20101122-01-RS

Lee, G. T., Kumar, I., Diers, B. W., and Hudson, M. E. 2015. Evolution and selection of Rhg1, a copy-number variant nematode-resistant locus. Mol. Ecol. 24:1774-1791.

Li, Y., Chen, S., and Young, N. D. 2004. Effect of the rhg1 gene on penetration, development, and reproduction of Heterodera glycines race 3. Nematology 6:729-736.

Lin, J., Mazarei, M., Zhao, N., Hatcher, C. N., Wuddineh, W. A., Rudis, M., Tschaplinski, T. J., Pantalone, V. R., Arelli, P. R., Hewezi, T., Chen, F., and Stewart, C. N., Jr. 2016. Transgenic soybean overexpressing GmSAMT1 exhibits resistance to multiple-HG types of soybean cyst nematode Heterodera glycines. Plant Biotechnol. J. Published online. doi:10.1111/ pbi.12566

Lin, J., Mazarei, M., Zhao, N., Zhu, J. J., Zhuang, X., Liu, W., Pantalone, V. R., Arelli, P. R., Stewart, C. N., Jr., and Chen, F. 2013. Overexpression of a soybean salicylic acid methyltransferase gene confers resistance to soybean cyst nematode. Plant Biotechnol. J. 11:1135-1145.

Liu, S., Kandoth, P. K., Warren, S. D., Yeckel, G., Heinz, R., Alden, J., Yang, C., Jamai, A., El-Mellouki, T., Juvale, P. S., Hill, J., Baum, T. J., Cianzio, S., Whitham, S. A., Korkin, D., Mitchum, M. G., and Meksem, K. 2012. A soybean cyst nematode resistance gene points to a new mechanism of plant resistance to pathogens. Nature 492:256-260.

Liu, W., Mazarei, M., Peng, Y., Fethe, M. H., Rudis, M. R., Lin, J., Millwood, R. J., Arelli, P. R., and Stewart, C. N., Jr. 2014. Computational discovery of soybean promoter cis-regulatory elements for the construction of soybean cyst nematode-inducible synthetic promoters. Plant Biotechnol. J. 12:10151026.

Liu, X., Liu, S., Jamai, A., Bendahmane, A., Lightfoot, D., Mitchum, M. G., and Meksem, K. 2011. Soybean cyst nematode resistance in soybean is independent of the Rhg 4 locus $L R R-R L K$ gene. Funct. Integr. Genomics 11: 539-549.

Lozano-Torres, J. L., Wilbers, R. H., Gawronski, P., Boshoven, J. C., Finkers-Tomczak, A., Cordewener, J. H., America, A. H. P., Overmars, H. A., Van't Klooster, J. W., Baranowski, L., Sobczak, M., Ilyas, M., van der Hoorn, R. A. L., Schots, A., de Wit, P. J. G. M., Bakker, J., Goverse, A., and Smant, G. 2012. Dual disease resistance mediated by the immune receptor Cf-2 in tomato requires a common virulence target of a fungus and a nematode. Proc. Natl. Acad. Sci. USA 109:10119-10124.

Mahalingam, R., and Skorupska, H. T. 1996. Cytological expression of early response to infection by Heterodera glycines Ichinohe in resistant PI 437654 soybean. Genome 39:986-998.

Mathieu, M., Winters, E. K., Kong, F., Wan, J., Wang, S., Eckert, H., Luth, D., Paz, M., Donovan, C., Zhang, Z., Somers, D., Wang, K., Nguyen, H., Shoemaker, R. C., Stacey, G., and Clemente, T. 2009. Establishment of a soybean (Glycine max Merr. L) transposon-based mutagenesis repository. Planta 229:279-289.

Matsye, P. D., Kumar, R., Hosseini, P., Jones, C. M., Tremblay, A., Alkharouf, N. W., Matthews, B. F., and Klink, V. P. 2011. Mapping cell fate decisions that occur during soybean defense responses. Plant Mol. Biol. 77:513-528.

Matthews, B. F., Beard, H., Brewer, E., Kabir, S., MacDonald, M. H., and Youssef, R. M. 2014. Arabidopsis genes, AtNPR1, AtTGA2, and AtPR-5, confer partial resistance to soybean cyst nematode (Heterodera glycines) when overexpressed in transgenic soybean roots. BMC Plant Biol. 14:96. 
Matthews, B. F., Beard, H., MacDonald, M. H., Kabir, S., Youssef, R. M., Hosseini, P., and Brewer, E. 2013. Engineered resistance and hypersusceptiblity through functional metabolic studies of 100 genes in soybean to its major pathogen, the soybean cyst nematode. Planta 237:1337-1357.

Mazarei, M., Liu, W., Al-Ahmad, H., Arelli, P., Pantalone, V. R., and Stewart, C. N., Jr. 2011. Gene expression profiling of resistant and susceptible soybean lines infected with soybean cyst nematode. Theor. Appl. Genet. 123:1193-1206.

Meksem, K., Pantazopoulos, P., Nijiti, V. N., Hyten, D., Arelli, P. R., and Lightfoot, D. A. 2001. 'Forrest' resistance to the soybean cyst nematode is bigenic: Saturation mapping of the Rhgl and Rhg4 loci. Theor. Appl. Genet. 103:710-717.

Melito, S., Heuberger, A. L., Cook, D., Diers, B. W., MacGuidwin, A. E., and Bent, A. F. 2010. A nematode demographics assay in transgenic roots reveals no significant impacts of the Rhgl locus LRR-kinase on soybean cyst nematode resistance. BMC Plant Biol. 10:104.

Milligan, S. B., Bodeau, J., Yaghoobi, J., Kaloshian, I., Zabel, P., and Williamson, V. M. 1998. The root knot nematode resistance gene $M i$ from tomato is a member of the leucine zipper, nucleotide binding, leucine-rich repeat family of plant genes. Plant Cell 10:1307-1320.

Mitchum, M. G., Wrather, J. A., Heinz, R. D., Shannon, J. G., and Danekas, G. 2007. Variability in distribution and virulence phenotypes of Heterodera glycines in Missouri during 2005. Plant Dis. 91:1473-1476.

Niblack, T. L., Colgrove, A. L., Colgrove, K., and Bond, J. P. 2008. Shift in virulence of soybean cyst nematode is associated with use of resistance from PI 88788. Plant Health Prog. Published online. 10.1094/PHP-20080118-01-RS

Niblack, T. L., Lambert, K. N., and Tylka, G. L. 2006. A model plant pathogen from the Kingdom Animalia: Heterodera glycines, the soybean cyst nematode. Annu. Rev. Phytopathol. 44:283-303.

Paal, J., Henselewski, H., Muth, J., Meksem, K., Menendez, C. M., Salamini, F., Ballavora, A., and Gebhardt, C. 2004. Molecular cloning of the potato Grol-4 gene conferring resistance to pathotype Rol of the root cyst nematode Globodera rostochiensis, based on a candidate gene approach. Plant J. 38:285-297.

Peng, D. L., Pend, H., Wu, D. Q., Huang, W. K., Ye, W. X., and Cui, J. K. 2016. First report of soybean cyst nematode (Heterodera glycines) on soybean from Gansu and Ningxia China. Plant Dis. 100:229.

Riggs, R. D., Kim, K. S., and Gipson, I. 1973. Ultrastructural changes in Peking soybeans infected with Heterodera glycines. Phytopathology 63: 76-84.
Schmutz, J., Cannon, S. B., Schlueter, J., Ma, J., Mitros, T., Nelson, W., Hyten, D. L., Song, Q., Thelen, J. J., Cheng, J., Xu, D., Hellsten, U., May, G. D., Yu, Y., Sakurai, T., Umezawa, T., Bhattacharyya, M. K., Sandhu, D., Valliyodan, B., Lindquist, E., Peto, M., Grant, D., Shu, S., Goodstein, D., Barry, K., Futrell-Griggs, M., Abernathy, B., Du, J., Tian, Z., Zhu, L., Gill, N., Joshi, T., Libault, M., Sethuraman, A., Zhang, X.-C., Shinozaki, K., Nguyen, H. T., Wing, R. A., Cregan, P., Specht, J., Grimwood, J., Rokhsar, D., Stacey, G., Shoemaker, R. C., and Jackson, S. A. 2010. Genome sequence of the palaeopolyploid soybean. Nature 463:178-183.

Shi, Z., Liu, S., Noe, J., Arelli, P., Meksem, K., and Li, Z. 2015. SNP identification and marker assay development for high-throughput selection of soybean cyst nematode resistance. BMC Genet. 16:314.

Tylka, G. L., and Marrett, C. C. 2014. Distribution of the soybean cyst nematode, Heterodera glycines, in the United States and Canada: 1954-2014. Plant Health Prog. 15:13-15.

Tylka, G. L., and Mullaney, M. P. 2015. Soybean cyst nematode-resistant soybeans for Iowa. Extension Publication PM 1649. Iowa State University Extension, Ames.

Wang, D., Arelli, P. R., Shoemaker, R. C., and Diers, B. W. 2001. Loci underlying resistance to Race 3 soybean cyst nematode in Glycine soja plant introduction PI468916. Theor. Appl. Genet. 103:561-566.

Wang, D., Duan, Y. X., Wang, Y. Y., Zhu, X. F., Chen, L. J., Liu, X. Y., and Chen, J. S. 2015a. First report of soybean cyst nematode, Heterodera glycines, on soybean from Guangxi, Guizhou, and Jiangxi Provinces, China. Plant Dis. 99:893.

Wang, H.-M., Zhao, H.-H., and Chu, D. 2015b. Genetic structure analysis of populations of the soybean cyst nematode, Heterodera glycines, from north China. Nematology 17:591-600.

Winstead, N. N., Skotland, C. B., and Sasser, J. N. 1955. Soybean cyst nematode in North Carolina. Plant Dis Rep. 39:9-11.

Wu, X.-Y., Zhou, G.-C., Chen, Y.-X., Wu, P., Liu, L.-W., Ma, F.-F., Wu, M., Liu, C.-C., Zeng, Y.-J., Chu, A. E., Hang, Y.-Y., Chen, J.-Q., and Wang, B. 2016. Soybean cyst nematode resistance emerged via artificial selection of duplicated serine hydroxymethyltransferase genes. Front. Plant Sci. 7:998.

Youssef, R. M., MacDonald, M. H., Brewer, E. P., Bauchan, G. R., Kim, K.-H., and Matthews, B. F. 2013. Ectopic expression of AtPAD4 broadens resistance of soybean to soybean cyst nematode and root-knot nematodes. BMC Plant Biol. 13:67.

Zhang, Y., Sun, K., Sandoval, F. J., Santiago, K., and Roje, S. 2010. Onecarbon metabolism in plants: Characterization of a plastid serine hydroxymethyltransferase. Biochem. J. 430:97-105. 